九州大学学術情報リポジトリ

Kyushu University Institutional Repository

\title{
Thermal conductivity of non-stoichiometric americium oxide : A molecular dynamics study
}

Uchida, Teppei

Nuclear Fuel Cycle Engineering Laboratories, Japan Atomic Energy Agency

Arima, Tatsumi

Department of Applied Quantum Physics and Nuclear Engineering, Faculty of Engineering, Kyushu University

Idemitsu, Kazuya

Department of Applied Quantum Physics and Nuclear Engineering, Faculty of Engineering, Kyushu University

Inagaki, Yaohiro

Department of Applied Quantum Physics and Nuclear Engineering, Faculty of Engineering, Kyushu University

http://hdl. handle. net/2324/26629

出版情報：Journal of Nuclear Materials. 400 (1)，pp.3-7，2010-05-01. Elsevier バージョン：

権利関係: (C) 2010 Elsevier B.V. 


\title{
Thermal conductivity of non-stoichiometric americium oxide: a molecular dynamics study
}

\author{
Teppei UCHIDA ${ }^{\mathrm{a}, \mathrm{b}}$, Tatsumi ARIMA ${ }^{\mathrm{a}^{*}}$, Kazuya IDEMITSU $^{\mathrm{a}}$, Yaohiro INAGAKI ${ }^{\mathrm{a}}$
}

${ }^{a}$ Department of Applied Quantum Physics and Nuclear Engineering, Faculty of Engineering, Kyushu University, 744 Motooka, Fukuoka 819-0395, Japan

${ }^{\mathrm{b}}$ Nuclear Fuel Cycle Engineering Laboratories, Japan Atomic Energy Agency, 4-33, Muramatsu, Tokai-mura, Naka-gun, Ibaraki 319-1194, Japan

\begin{abstract}
The aim of this paper is to investigate the influence of multi-valency of americium in its oxide for the lowering of the thermal conductivity and the uncertainty in measurement. In the present study, thermal conductivity of non-stoichiometric americium oxide was evaluated up to $2000 \mathrm{~K}$ by the non-equilibrium molecular dynamics calculations using the Born-Mayer-Huggins interatomic potential with the partially ionic model. The oxygen-to-americium ratio $(\mathrm{O} / \mathrm{Am})$ was varied from 1.6 to 1.9 , which corresponded to the variation of the ratio of $\mathrm{Am}^{3+} / \mathrm{Am}^{4+}$. So, we prepared potential parameters for both $\mathrm{Am}^{3+}$ and $\mathrm{Am}^{4+}$. The calculated thermal conductivity of non-stoichiometric americium oxide decreased with an increase of temperature, and the degree of the temperature dependence became smaller with a decrease of the O/Am ratio. This was mainly caused by the phonon-scattering due to oxygen vacancies induced with $\mathrm{Am}^{3+}$ ions. Comparing two supercells in which (1) short-range ordered $\mathrm{Am}^{3+}$ clusters were contained and (2) $\mathrm{Am}^{3+}$ ions were randomly distributed, the thermal conductivity of the former seemed to be somewhat lager than that of the latter.
\end{abstract}

\footnotetext{
* Corresponding author

E-mail: arima@ nucl.kyushu-u.ac.jp

Tel: +81-92-802-3494

Fax: +81-92-802-3494
} 
Keywords: americium oxide, thermal conductivity, thermal expansion, molecular dynamics simulations

PACS codes: 28.41.Bm, 28.41.Ak, 05.70.-a, 82.60.-s 


\section{Introduction}

For a nuclear fuel cycle, minor actinides (MA: $\mathrm{Np}, \mathrm{Am}, \mathrm{Cm}$ ) are the key elements because these are possible to be used as MOX containing MA, or disposed a transuranic waste. In a novel concept for the nuclear transmutation system, these MA might be used as a target fuel, e.g. CERCER (ceramic-ceramic) or CERMET (ceramic-metal) fuel. Especially, americium isotopes have the high and lasting radiotoxicity. In addition, an americium ion shows the multi-valency in the oxide form from the view of a chemical property [1]. For high temperatures like a fuel operating temperature, the oxidation state of the americium ion is sensitive to oxygen partial pressure. As a result, the americium oxide often forms to be the mixture of dioxide and sesquioxide. Therefore, there were sometimes discrepancies among the empirical, semi-empirical and theoretical assessments [2-11]. For example, the literature data of the thermal conductivity of americium dioxide varied from ca. 3 to $9 \mathrm{~W} \cdot \mathrm{m}^{-1} \mathrm{~K}^{-1}$ around $300 \mathrm{~K}[3,9,10]$.

We have evaluated various thermal properties of actinide oxides, e.g. uranium oxides and plutonium oxides and their solid solution by the molecular dynamics (MD) simulation so far [12-14]. Recently, thermal properties of stoichiometric $\mathrm{AmO}_{2}$ and $\mathrm{Am}_{2} \mathrm{O}_{3}$ have been reported [15]. And also, other researchers have demonstrated the validity of MD simulation for the analyses of thermal properties such as thermal expansion, heat capacity, thermal conductivity and so on $[10,12,13]$. Especially for the thermal conductivity, we have developed non-equilibrium MD (NEMD) method as the alternative simulation technique for equilibrium MD (EMD) method and have evaluated the effect of oxygen non-stoichiometry in oxide fuels [14]. In the present study, we therefore performed NEMD simulations for non-stoichiometric americium oxide $\mathrm{AmO}_{2-x}(x<0.5)$ in order to systematically investigate thermal conductivities. 


\section{Molecular dynamics simulation}

\subsection{Interatomic potential function and non-equilibrium molecular dynamics simulation}

In the present study, the MXDORTO program customized for the calculation of the thermal conductivity in non-equilibrium system was used in the MD simulation, and the original code was developed by Kawamura et al. [16]. Here we employed the Born-Mayer-Huggins (BMH) interatomic potential with the partially ionic model (PIM) to each ion pair in crystals. The interatomic potential function consists of three terms of Coulomb interaction, repulsive short-range interaction and van der Waals interaction.

$U_{\mathrm{PIM}}\left(r_{i j}\right)=\frac{z_{i} z_{j} e^{2}}{r_{i j}}+f_{0}\left(b_{i}+b_{j}\right) \exp \left(\frac{a_{i}+a_{j}-r_{i j}}{b_{i}+b_{j}}\right)-\frac{c_{i} c_{j}}{r_{i j}^{6}}$,

where $f_{0}\left(=6.9511 \times 10^{-11} \mathrm{~N}\right)$ is an adjustable parameter. Potential parameters, $a_{i}, b_{i}$ and $c_{i}$, are associated with an ion of type $i$. In Eq. (1), $z_{i}$ is the effective charge of a type $i$ ion, and an ionic bonding of $67.5 \%$ is assumed for each ion in the present simulated system [12-15,17,18]. In order to calculate the thermal conductivity of non-stoichiometric americium oxide, we needed the potential parameters for both $\mathrm{Am}^{4+}-\mathrm{O}^{2-}$ and $\mathrm{Am}^{3+}-\mathrm{O}^{2-}$ systems. In the previous study [15], these potential parameters were determined to reproduce lattice structures, thermal expansions and bulk moduli experimentally obtained for fluorite $\mathrm{AmO}_{2}$ and cubic bixbyite $\mathrm{Am}_{2} \mathrm{O}_{3}$ crystals [1,2,5-7,19-21] Potential parameters summarized in Table 1 were adequate for $\mathrm{AmO}_{2}$, however these gave a little small bulk modulus of $\mathrm{Am}_{2} \mathrm{O}_{3}$.

As one of the alternatives to the EMD method, the homogeneous NEMD one proposed by Evans [22] was applied to calculate the thermal conductivity in the present study. It gave the small errors of the thermal conductivities than the EMD at low temperatures. Errors in the EMD 
calculations were originated from the large fluctuation of the auto-correlation function of the heat fluxes [15]. As described below, the NEMD method can be kept away from such a drawback. In the homogeneous NEMD scheme, dynamics of the particles in the simulated cell are governed by the following equations of motion:

$$
\begin{aligned}
& \frac{d \vec{q}_{i}}{d t}=v_{i} \\
& \frac{d \vec{p}_{i}}{d t}=\vec{F}_{i}+\vec{D}_{i} \vec{F}_{e x t}(t),
\end{aligned}
$$

where $\vec{q}_{i}$ and $\vec{p}_{i}$ are the generalized coordinate and momentum of $i$-th particle, $v_{i}$ the velocity, $\vec{F}_{i}$ the force, $\vec{F}_{e x t}$ the perturbed external force field parameter coupled with $\vec{D}_{i}$ the tensor parameter. Here, $\vec{D}_{i}$ means the deviation energy of $i$-th particle from average of energy in the $N$-particle system [23]. For $\quad \vec{F}_{\text {ext }}=\left(F_{\text {ext }}, 0,0\right)$, the thermal conductivity in $x$ direction is written by

$\kappa=\lim _{F_{e x t} \rightarrow 0} \lim _{t \rightarrow \infty} \frac{\left\langle\vec{j}_{E}(t)\right\rangle}{V T F_{\text {ext }}}$.

Therefore, in the NEMD scheme, the thermal conductivity is defined as the proportional constant between the time-averaged energy current (heat flux) and the perturbed external force field parameter. In the above equations, $\vec{j}_{E}(t)$ is generally written by

$$
\vec{j}_{E}(t)=\sum_{i=1}^{N}\left[\frac{m_{i} v_{i}^{2}}{2}+\frac{1}{2} \sum_{j \neq i} U\left(r_{i j}\right)\right] \vec{v}_{i}+\frac{1}{2} \sum_{i=1}^{N} \vec{v}_{i} \cdot \vec{r}_{i j} \vec{F}_{i j} .
$$

The energy current in the Coulomb system for the present study was given by Bernu [24]. In the EMD, the calculation of the auto-correlation functions of energy currents expressed in Eq. (5) was 
required, but not required in the NEMD [15].

\subsection{Supercells and simulation procedure}

In the present study, we prepared two types of supercells for $\mathrm{AmO}_{2-\mathrm{x}}$ crystal. One is the supercell contains the short-range ordered cation clusters, which are tetrahedrons consisting of $\mathrm{Am}^{3+}$. Hereafter, this supercell is called SC1 and is shown in Fig. 1 (a). For the initial configuration of the $\mathrm{SC} 1$ supercell, $1 / 8$ unit cell of bixbyite $\mathrm{Am}_{2} \mathrm{O}_{3}\left(\mathrm{Am}^{3+}\right.$ ions: $\left.4, \mathrm{O}^{2-}: 6\right)$ and a unit cell of fluorite $\mathrm{AmO}_{2}$ ( $\mathrm{Am}^{4+}$ ions: $4, \mathrm{O}^{2-}: 8$ ) were mixed for the specified $\mathrm{O} / \mathrm{Am}$ ratio because the lattice constant of bixbyite is about twice as large as that of fluorite. Thus, cubic SC1 supercell consisted of less than 1500 ions but number of cations was strictly 500. The other is one in which $\mathrm{Am}^{3+}$ ions were randomly substituted for $\mathrm{Am}^{4+}$ ions on cation sub-lattice sites of $5 \times 5 \times 5$ fluorite unit cells, which means the positions of $\mathrm{Am}^{3+}$ ions were given by random numbers generated by a computer. Subsequently, $\mathrm{O}^{2-}$ ions were removed in accordance with the amount of $\mathrm{Am}^{3+}$ ions. This supercell is called SC2 and is shown in Fig. 1 (b). According to the phase diagram of Am-O system, in the O/Am range between 1.6 and 1.9, fluorite $\mathrm{AmO}_{2-\mathrm{x}}$ dominates above roughly $1100 \mathrm{~K}$, however bixbyite $\mathrm{Am}_{2} \mathrm{O}_{3+\mathrm{y}}$ and fluorite $\mathrm{AmO}_{2-\mathrm{x}}$ coexists at low temperatures [25]. Unfortunately, experimental results are rather restricted for studies of the phase diagram. Of course, the configurations of lattice defects are not understood sufficiently for this system. Therefore, although two types of supercell described above might not reflect the defect configuration actually formed in the real crystal, we made such an assumption, i.e. $\mathrm{SC} 1$ and $\mathrm{SC} 2$.

The homogeneous NEMD calculation was performed under the periodic boundary conditions, and temperature of the system was controlled with the Nóse thermostat. The thermostat mass was $1 \times 10^{-13} \mathrm{~kg} \cdot \mathrm{m}^{2}$ [16]. Following the initial relaxation calculation with $2 \times 10^{4}$ steps $(=40 \mathrm{ps})$, the NEMD simulation was performed for $5 \times 10^{4}$ steps $(=100 \mathrm{ps})$ in the $N V T$ ensemble for 5 or 6 
different $F_{\text {ext }}$ values and directions of $x, y$ and $z$. During the calculation, the supercell shape was kept to cubic even for the system including oxygen vacancies.

\section{Results and discussion}

Fig. 2 shows the $\mathrm{O} / \mathrm{Am}$ dependence of lattice constant of $\mathrm{AmO}_{2-\mathrm{x}}$ around $300 \mathrm{~K}$. In this figure, the experimental result and Vegard's law, which is predicted by a mixture of bixbyite and fluorite, are plotted, together with the results obtained from NEMD calculations. The experimental result by Chikalla clearly shows the coexistence of hyperstoichiometric bixbyite and stoichiometric fluorite [25]. Our calculated results are in good agreement with experimental one and Vegard's law, and the lattice constants of $\mathrm{SC} 1$ and $\mathrm{SC} 2$ increase with a decrease of $\mathrm{O} / \mathrm{Am}$ ratio, which is that the substitution of $\mathrm{Am}^{3+}$ with inducing oxygen vacancies results in an increase of the lattice constant. The difference in lattice constant between SC1 and SC2 are rather small. Such a tendency was caused from an expansion of the distance between nearest-neighbor (NN) oxygen ions. The pair correlation function of O-O shows in Fig. 3. Although the difference between SC1 and SC2 cannot be observed, $\mathrm{NN}$ distance apparently increases with decreasing $\mathrm{O} / \mathrm{Am}$ ratio.

The thermal conductivities of non-stoichiometric oxides were evaluated by NEMD calculations. The calculated thermal conductivity was determined by Eq. (4). For $\mathrm{AmO}_{1.8}$, the relationship between the time-averaged heat flux and the perturbed external force field parameter is shown in Fig. 4. The value of the heat flux increases with respect to $F_{e x t}$, which means the linear response between the heat flux and $F_{e x t}$. When too large $F_{\text {ext }}$ was applied to the system, the linear response broke down. The slope of the linear relation observed decreases with an increase of temperature because of phonon-phonon interaction (Umklapp process) at high temperatures.

In the previous study, we reported that the calculated thermal conductivity of $\mathrm{AmO}_{2}$ was 
comparable with that of $\mathrm{UO}_{2}$ [26] and was inversely proportional to temperature, whereas that of $\mathrm{Am}_{2} \mathrm{O}_{3}$ was ca. $0.8 \mathrm{~W} \cdot \mathrm{m}^{-1} \mathrm{~K}^{-1}$ regardless of temperature [15]. The calculated thermal conductivities of $\mathrm{AmO}_{2-\mathrm{x}}$ are shown in Fig. 5, together with the literature data. The low thermal conductivity less than $1.0 \mathrm{~W} / \mathrm{m} / \mathrm{K}$ was measured for $\mathrm{AmO}_{2-\mathrm{x}}$ by Schmidt, where oxygen deficiency $x$ was unclear [8]. Recently, the temperature dependence of thermal conductivity of $\mathrm{AmO}_{2-\mathrm{x}}$ was reported by Nishi et al. [3]. The reported $\mathrm{O} / \mathrm{Am}$ ratio varied from 1.73 to 1.90 . The $\mathrm{MD}$ calculation seems to be comparable with experimental data measured by Nishi et al. [3], and predicts that the $\mathrm{O} / \mathrm{Am}$ ratio is near 1.5 for Schmidt's experiment [8]. At the O/Am ratio of 1.9 , the calculated thermal conductivity clearly decreases with an increase of temperature for both $\mathrm{SC} 1$ and $\mathrm{SC} 2$. With decreasing the $\mathrm{O} / \mathrm{Am}$ ratio, the thermal conductivity decreases, and the degree of the temperature dependence also decreases, which means that at high $\mathrm{O} / \mathrm{Am}$ ratios, both Umklapp process and phonon-defect interaction contribute to the lowering of thermal conductivity, whereas at low $\mathrm{O} / \mathrm{Am}$ ratios, the phonon-defect interaction dominates. Furthermore, from the point of view of the defect configuration, the thermal conductivity of $\mathrm{SC} 1$ is higher than that of $\mathrm{SC} 2$ for the $\mathrm{O} / \mathrm{Am}=1.9$ at low temperatures but is almost same for small O/Am ratios. Fig. 6 shows the oxygen coordination number $(\mathrm{CN})$ of $\mathrm{Am}^{3+}$ or $\mathrm{Am}^{4+}$ ion, which figures out the local defect configuration around a cation. At $300 \mathrm{~K}$, the initial configuration still remains even after the relaxation calculation because oxygen cannot move around in the supercell (Fig. 6 (a)). As a result, the difference in $\mathrm{CN}$ for SC1 can be clearly observed between $\mathrm{Am}^{3+}$ and $\mathrm{Am}^{4+}$. On the other hand, such a difference cannot be observed for $\mathrm{SC} 2$, and $\mathrm{CN}$ is almost same as one given by ideal solid solution, i.e. random distributions of $\mathrm{Am}^{3+}$ ions and oxygen vacancies. At $2000 \mathrm{~K}$ (Fig. 6 (b)), the difference in CN between SC1 and SC2 becomes small because oxygen can easily move around. However, the defect configuration of SC1 still remains at $2000 \mathrm{~K}$. Therefore, although a local configuration of defects is different between SC1 and SC2, the thermal conductivity is almost same for the $\mathrm{O} / \mathrm{Am} \leq 1.8$ at even low temperatures. It seems that the 
oxygen deficiency, $x$, simply effects the thermal conductivity of $\mathrm{AmO}_{2-\mathrm{x}}$, where $x \geq 0.2$. Here, oxygen vacancy and $\mathrm{Am}^{3+}$ ion, both contribute to oxygen deficiency. Although the interatomic potential function is different between $\mathrm{Am}^{4+}$ and $\mathrm{Am}^{3+}$ ions, both ions occupy the cation sub-lattice sites and cause little alteration of its lattice structure. On the other hand, oxygen vacancies cause the significant alteration of anion sub-lattice structure. Therefore, it is highly possible that oxygen vacancies more contribute to the lowering of thermal conductivity than $\mathrm{Am}^{3+}$ ions if the phonon dispersion of $\mathrm{AmO}_{2}$ is almost kept even for the system where some defects are introduced, i.e. $\mathrm{AmO}_{2-\mathrm{x}}$. The following discussion is also based on this hypothesis.

In general, the thermal conductivity can be expressed in $(A+B \cdot T)^{-1}$, where $A$ and $B$ are constants, $T$ is temperature. $A$ is the thermal resistance caused by the phonon-defect interaction while $B \cdot T$ is one caused by the phonon-phonon interaction. The values of $A$ and $B$, which are estimated from thermal conductivities in Fig. 5, are plotted as a function of the O/Am ratio in Figs. 7 (a) and (b), respectively. Our calculated results show that $A$ of stoichiometric $\mathrm{AmO}_{2}$ is almost zero and increases with a decrease of the $\mathrm{O} / \mathrm{Am}$ ratio, which is interpreted that oxygen deficiency strongly effects the lowering of thermal conductivity at the wide range of the O/Am ratio. These results mean that the thermal conductivity of stoichiometric $\mathrm{AmO}_{2}$ well obeys the above thermal resistance model. Furthermore, the thermal resistance $A$ of cubic $\mathrm{Am}_{2} \mathrm{O}_{3}$ is not zero, which means that if the lattice structure of $\mathrm{AmO}_{2}$ is ideal fluorite, that of $\mathrm{Am}_{2} \mathrm{O}_{3}$ is considered to be deformed fluorite or fluorite including defects. It is because the crystal structure of $\mathrm{Am}_{2} \mathrm{O}_{3}$ is bixbyite and positions of $\mathrm{Am}$ and $\mathrm{O}$ ions except for oxygen vacancies in $\mathrm{Am}_{2} \mathrm{O}_{3}$ are almost same as those of fluorite $\mathrm{AmO}_{2}$. On the other hand, $B$ values for $\mathrm{O} / \mathrm{Am}=1.9$ are comparable with that of $\mathrm{AmO}_{2}$, whereas at $\mathrm{O} / \mathrm{Am} \leq 1.8$, these values are almost same as that of $\mathrm{Am}_{2} \mathrm{O}_{3}$. Hence, in the Am-O system, the temperature dependence of thermal conductivity is rapidly decreased with an increase of oxygen deficiency, and as a result, the thermal conductivity of $\mathrm{AmO}_{2-\mathrm{x}}$ approaches to that of $\mathrm{Am}_{2} \mathrm{O}_{3}$. 


\section{Conclusions}

In the present study, the thermal conductivity of $\mathrm{AmO}_{2-\mathrm{x}}$ was evaluated by NEMD simulation using the BMH potential function with the PIM. The thermal conductivity was obtained as the proportional constant between the energy current and the perturbed external force field parameter in the homogeneous NEMD system. The calculated results were almost comparable with experimental results obtained from $\mathrm{AmO}_{2-\mathrm{x}}$. Considering the $\mathrm{O} / \mathrm{Am}$ ratio dependence, the thermal conductivity calculated from NEMD simulation decreases with an increase of temperature at $\mathrm{O} / \mathrm{Am} \geq 1.9$ and almost constant with respect to temperature at $\mathrm{O} / \mathrm{Am} \leq 1.8$, which means that both phonon-phonon and phonon-defect interactions contributes to the lowering of thermal conductivity at high O/Am ratios and the phonon-defect interaction dominates it at low O/Am ratios. From the point of view of defect configurations, under the condition of $\mathrm{O} / \mathrm{Am}=1.9$ and low temperatures, $\mathrm{SC} 1$ supercell with $\mathrm{Am}^{3+}$ tetrahedron clusters has higher thermal conductivity than SC2 supercell in which $\mathrm{Am}^{3+}$ and oxygen vacancies were randomly distributed. For other conditions, almost comparable results were obtained for SC1 and SC2 supercells. This is the reason why the partially coherent phonon propagates in crystal for the former condition since the local defect configuration still remains, whereas the phonon propagation is strongly disturbed by defects, i.e. oxygen vacancies, under the latter condition.

\section{Acknowledgements}

The authors would like to thank Kawamura for usage of the MXDORTO source code. 


\section{References}

[1] E. H. P. Cordfunke, R. J. M. Konings, Thermochemical Data for Reactor Materials and Fission Products (North-Holland, Amsterdam, 1990).

[2] J. A. Fahey, Inorg. Nucl. Chem. Letters 20 (1974) 459.

[3] T. Nishi, M. Takano, A. Itoh, M. Akabori, Y. Arai, K. Minato, M. Numata, J. Nucl. Mater. 373 (2008) 295 .

[4] K. Minato, M. Takano, T. Nishi, A. Itoh, M. Akabori, Recent Advances in Actinide Science (2006) 317.

[5] J. P. Dancausse, E. Gering, S. Heathman, U. Benedict, J. Nucl. Sci. Technol. Suppl. 3 (2002) 136.

[6] S. Li, R. Ahuja, B. Johansson, High Press. Res. 22 (2002) 471.

[7] M. Idiri, T. L. Bihan, S. Heathman, J. Rebizant, Phys. Rev. B70 (2004) 14113.

[8] H. E. Schmidt, Proc. 4ième Journées d'Actinides, Harwell, UK, 1974, Atomic Energy Research Establishment report AERE-R-7961, 1975.

[9] K. Bakker, R. J. M. Konings, J. Nucl. Mater. 254 (1998) 129.

[10] S.E. Lemehov, V. Sobolev, P. Van Uffelen, J. Nucl. Mater. 320 (2003) 66.

[11] K. Kurosaki, M. Imamura, I. Sato, T. Namekawa, M. Uno, S. Yamanaka, J. Nucl. Sci. Technol. $41(2004) 827$.

[12] T. Arima, S. Yamasaki, Y. Inagaki, K. Idemitsu, J. Alloys and Compd. 400 (2005) 43.

[13] T. Arima, S. Yamasaki, Y. Inagaki, K. Idemitsu, J. Alloys Comp. 415 (2006) 43.

[14] T. Arima, S. Yamasaki, K. Idemitsu, Y. Inagaki, J. Nucl. Mater. 376 (2008) 139.

[15] T. Uchida, T. Arima, K. Idemitsu, Y. Inagaki, Comp. Mater. Sci. 45 (2009) 229.

[16] K. Hirao, K. Kawamura, Material Design Using Personal Computer, Shokabo, Tokyo (1994).

[17] H. Inaba, R. Sagawa, H. Hayashi, K. Kawamura, Solid State Ionics 122 (1999) 95. 
[18] H. Hayashi, R. Sagawa, H. Inaba, K. Kawamura, Solid State Ionics 131 (2000) 281.

[19] C. Thiriet, R. J. M. Konings, J. Nucl. Mater. 320 (2003) 292.

[20] D. Taylor, Br. Ceram. Trans. J. 83 (1984) 92.

[21] R.D. Shannon, Acta Cryst. A32 (1976) 751.

[22] D.J. Evans, G.P. Morriss, Statistical Mechanics of Nonequilibrium Liquids, Academic, London (1990).

[23] S. Motoyama, Y. Ichikawa, Y. Hiwatari, A. Oe, Phys. Rev. B 60 (1999) 292.

[24] B. Bernu, P. Vieillefosse, Phys. Rev. A18 (1978) 2345.

[25] T.D. Chikalla, L. Eyring, J. Inorg. Nucl. Chem. 30 (1968) 133.

[26] S. Fukushima, T. Ohmichi, A. Maeda, M. Honda, J. Nucl. Mater. 115 (1983) 118. 


\section{Figure captions}

Fig. 1. Simulated supercells in which (a) tetrahedron consisting of $\mathrm{Am}^{3+}$ contained (SC1); (b) $\mathrm{Am}^{3+}$ randomly distributed (SC2). Large green ball stands for $\mathrm{O}^{2-}$, small blue one $\mathrm{Am}^{4+}$ and light blue one $\mathrm{Am}^{3+}$. Each enlarged image of defect configuration is also shown here.

Fig. 2. Lattice constants of $\mathrm{AmO}_{2-\mathrm{x}}$ as a function of the $\mathrm{O} / \mathrm{Am}$ ratio around $300 \mathrm{~K}$.

Fig. 3. Pair-correlation function (PCF) of O-O ions as a function of distance for (a) SC1 and (b) SC2 supercells.

Fig. 4. Heat flux of $\mathrm{AmO}_{1.8}$ as a function of perturbed external force field.

Fig. 5. Thermal conductivity obtained from NEMD calculation for $\mathrm{AmO}_{2-\mathrm{x}}$ as a function of temperature.

Fig. 6. Oxygen coordination number $(\mathrm{CN})$ as a function of O/Am ratio for (a) $300 \mathrm{~K}$ and (b) $2000 \mathrm{~K}$.

Fig. 7. $A$ (a) and $B$ (b) constants as a function of $\mathrm{O} / \mathrm{Am}$ ratio. Here, the temperature dependence of thermal conductivity is given by $(A+B \cdot T)^{-1}$. 
Table

Table 1. Potential parameters of the Am-O system

\begin{tabular}{cccccc}
\hline Ion & $z_{i}$ & $a_{i}[\mathrm{~nm}]$ & $b_{i}[\mathrm{~nm}]$ & $c_{i}\left[\mathrm{~J}^{0.5} \cdot \mathrm{nm}^{3} \cdot \mathrm{mol}^{-0.5}\right]$ & Reference \\
\hline $\mathrm{Am}^{4+}$ & 2.7 & 0.1282 & 0.00373 & 0.0 & {$[15]$} \\
$\mathrm{Am}^{3+}$ & 2.025 & 0.1271 & 0.00301 & 0.0 & {$[15]$} \\
$\mathrm{O}^{2-}$ & -1.35 & 0.1847 & 0.01660 & 1.294 & {$[17,18]$} \\
\hline
\end{tabular}




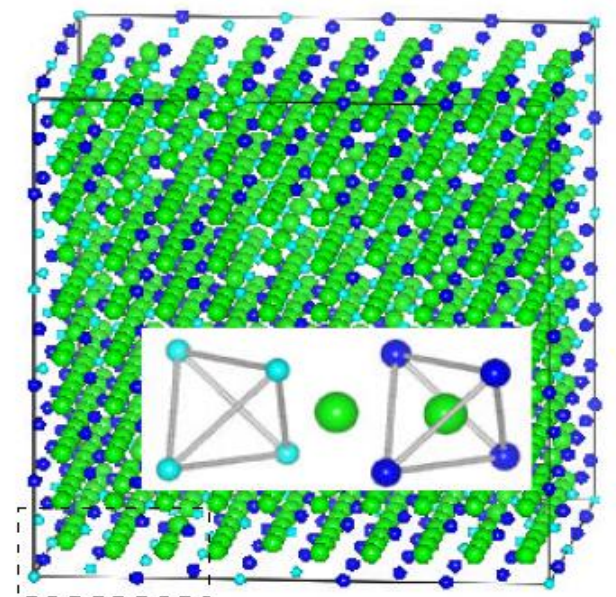

(a)

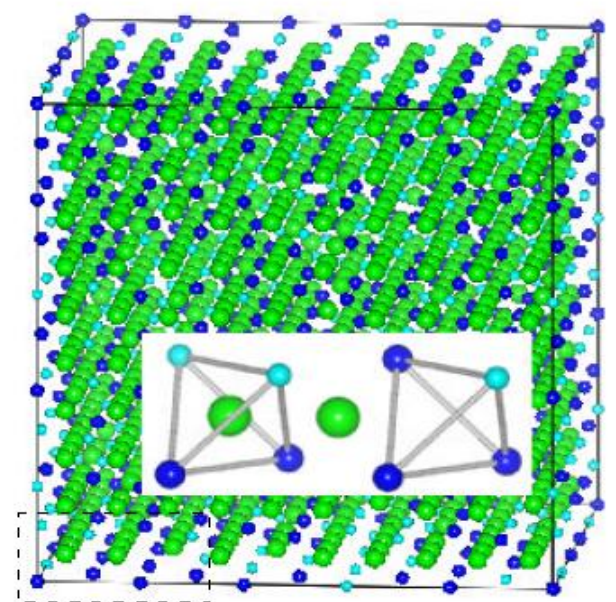

(b)

Fig. 1 


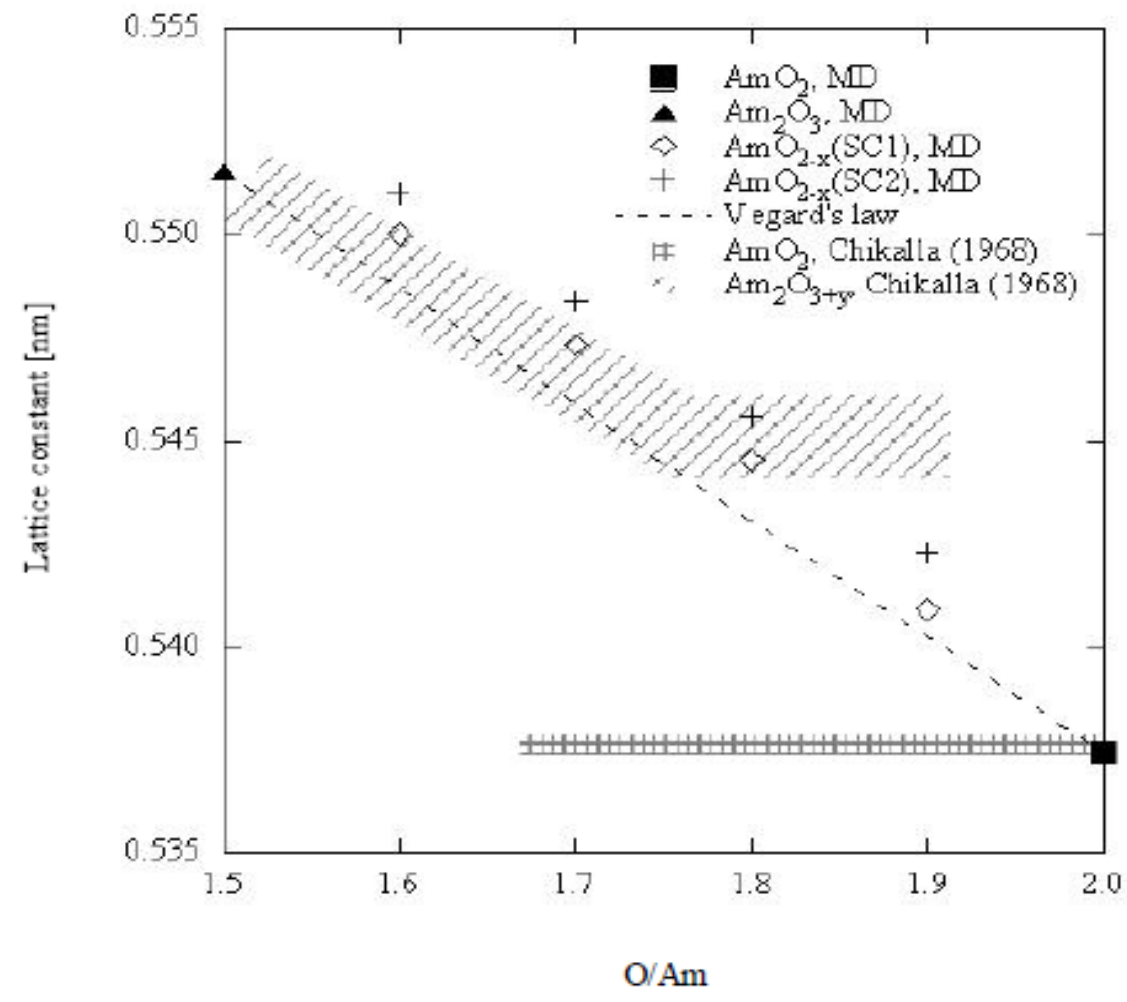

Fig. 2 


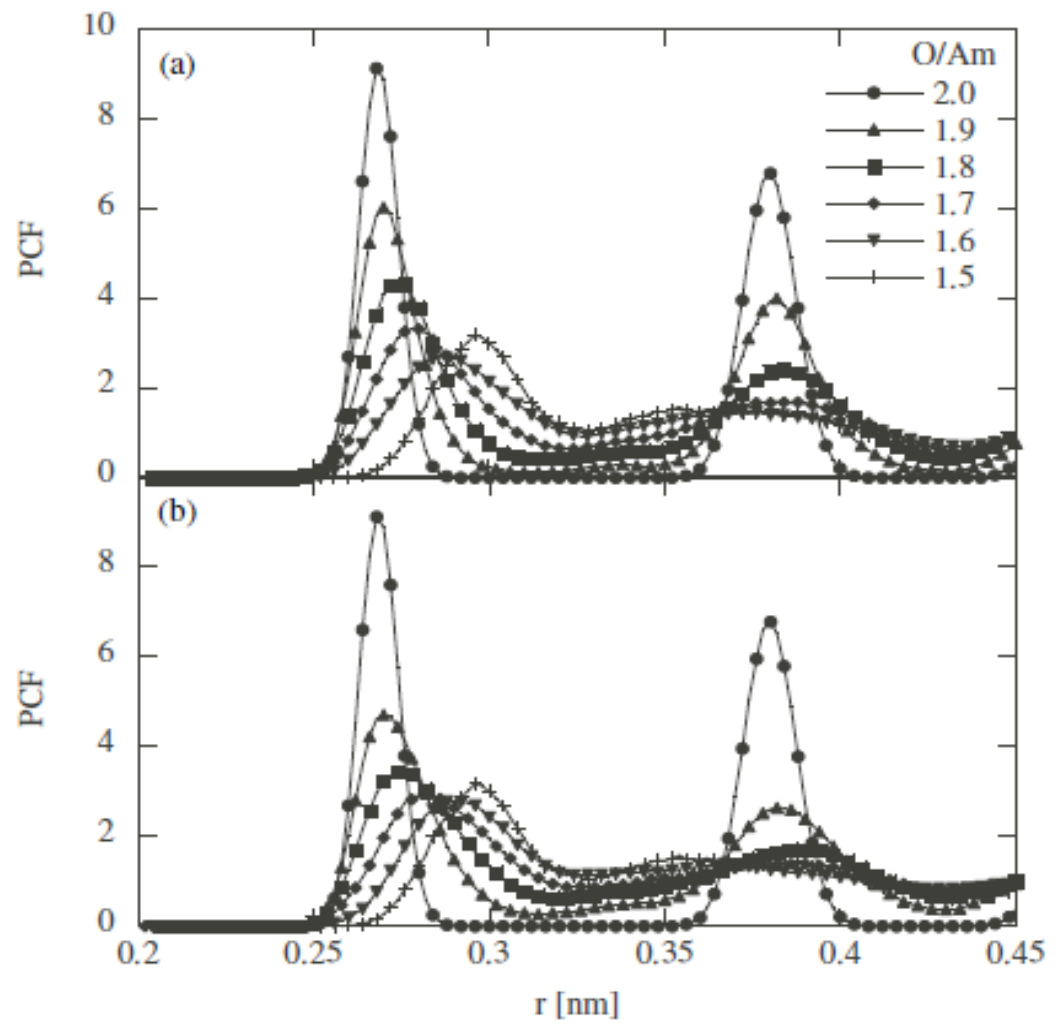

Fig. 3 


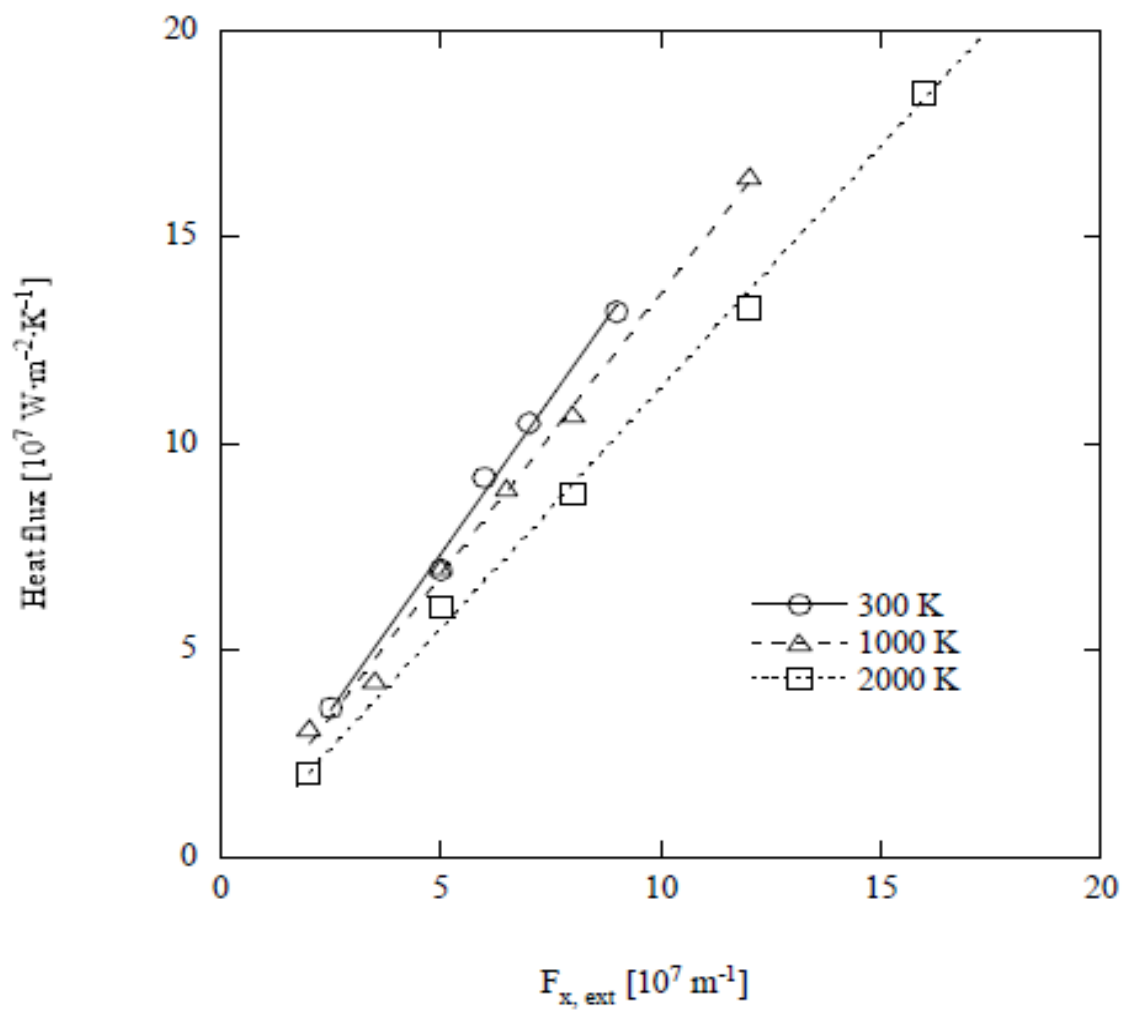

Fig. 4 


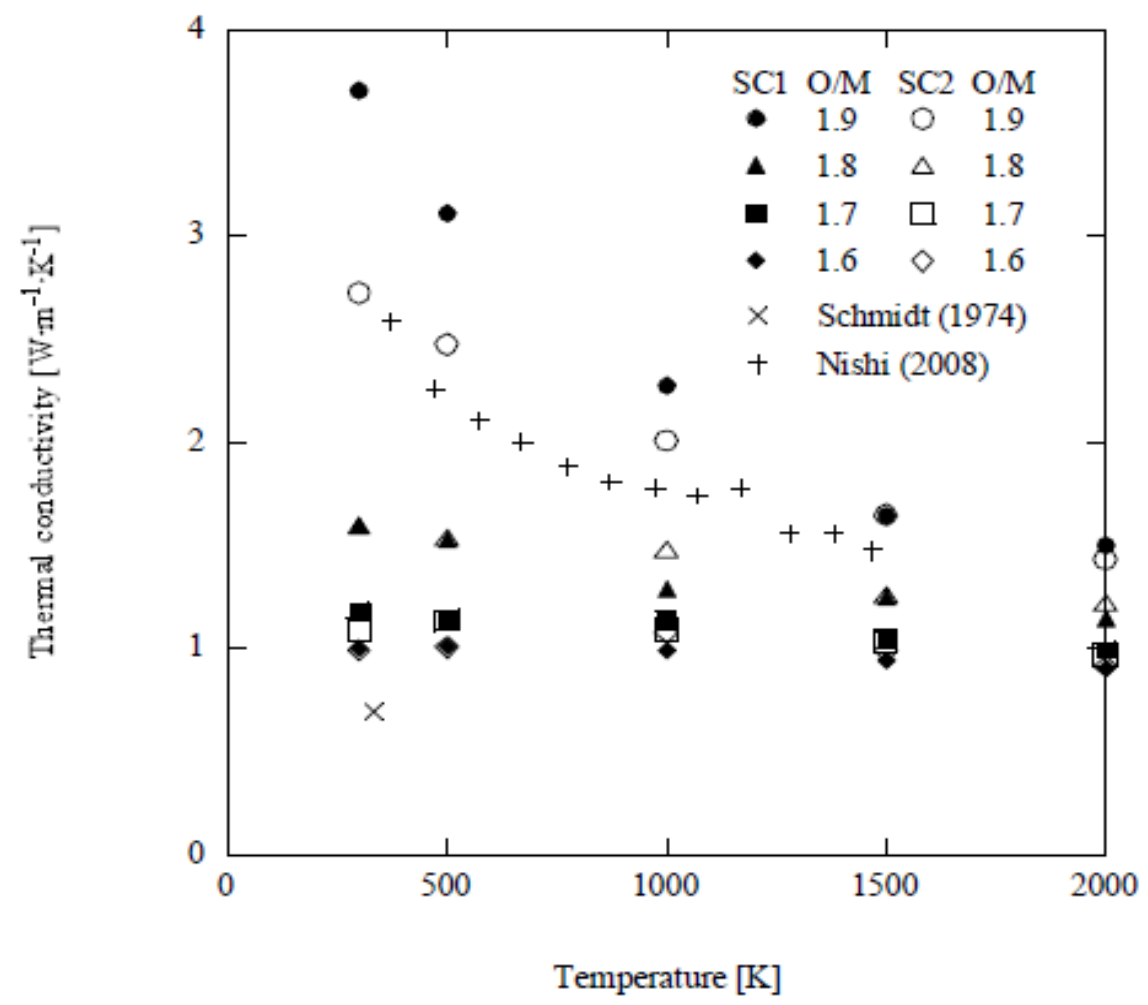

Fig. 5 


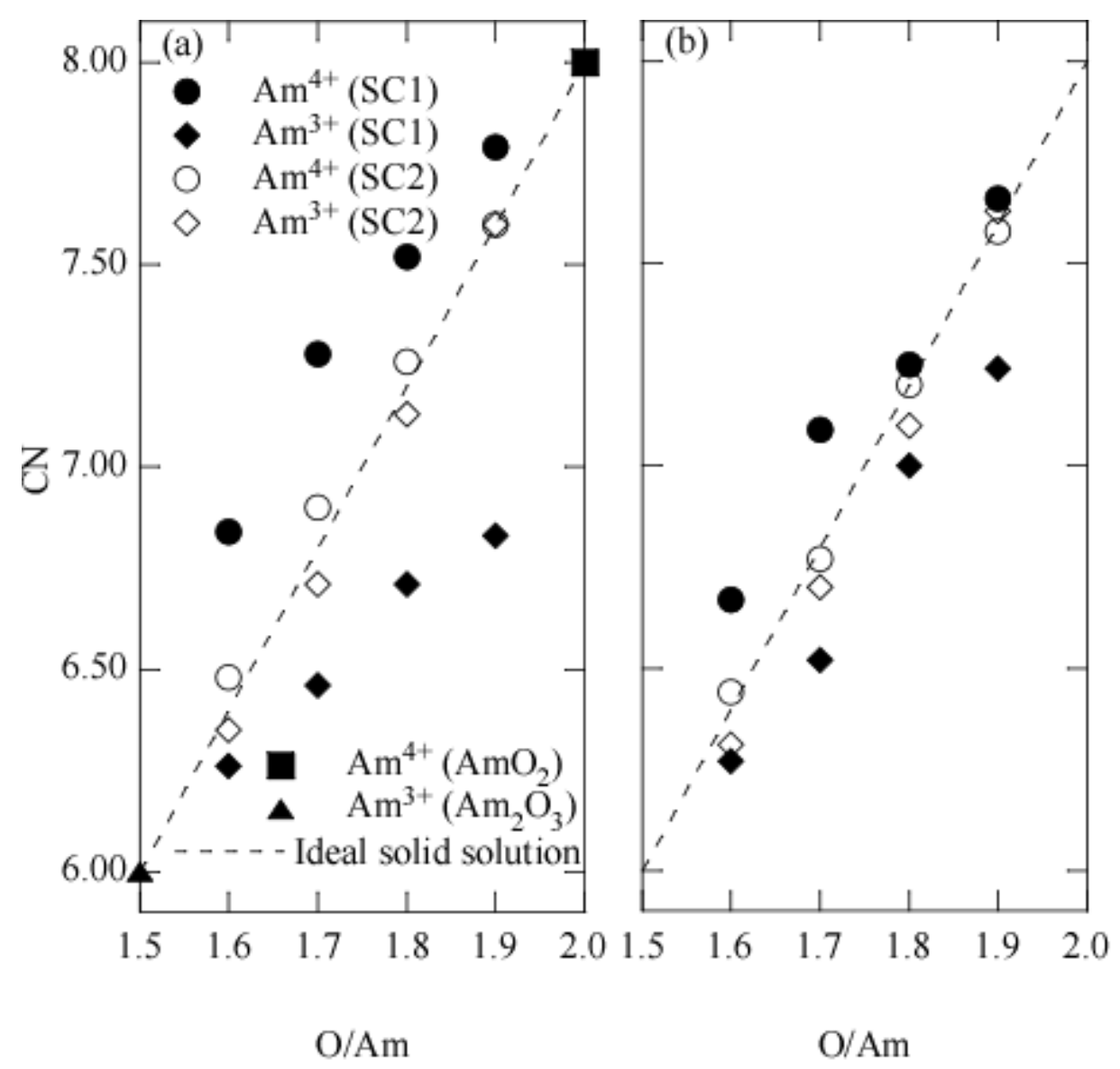

Fig. 6 

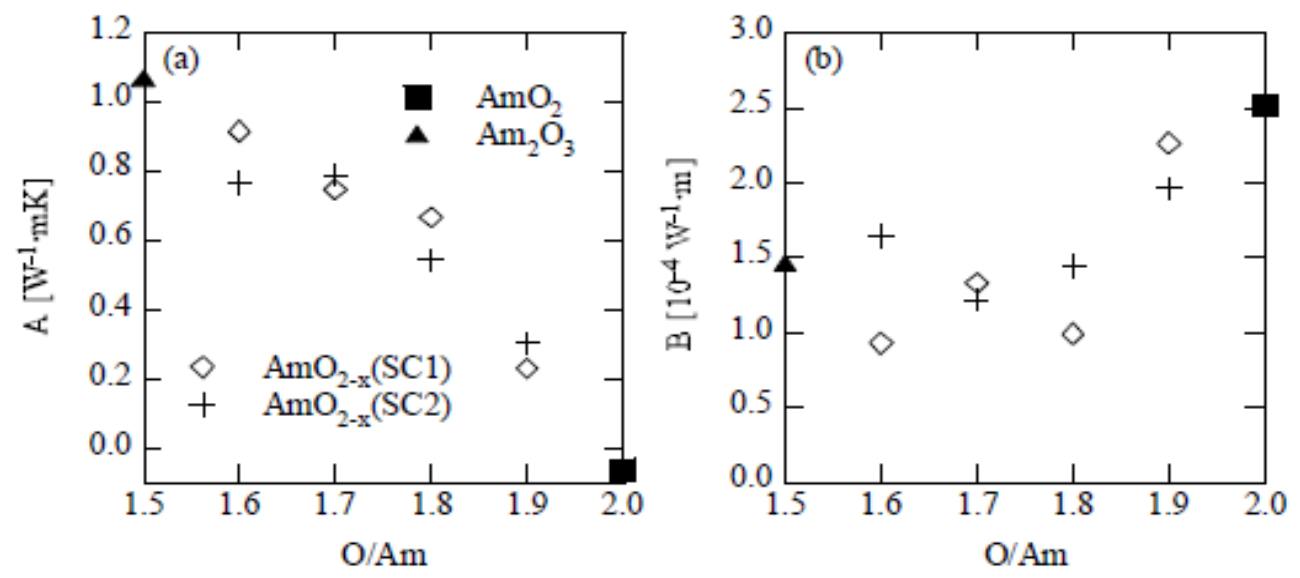

Fig. 7 